Article

\title{
Where Do We Draw the Line? Interlopers, (Ant)agonists, and an Unbounded Journalistic Field
}

\author{
Scott A. Eldridge II \\ Centre for Media and Journalism Studies, University of Groningen, 9712 EK Groningen, The Netherlands; \\ E-Mail: s.a.eldridge.ii@rug.nl
}

Submitted: 22 June 2019 | Accepted: 6 November 2019 | Published: 17 December 2019

\begin{abstract}
Journalism's once-neglected periphery has been a focus of academic research in recent years and the urge to make sense of interlopers from the periphery has brought about many approaches to understanding these changes. In this essay I reflect on an ongoing research agenda examining one particular category of interlopers: provocative media actors who have openly challenged the boundaries of the journalistic field. These actors raise questions as to how to account for interlopers at the edges of the journalistic field, including whether we should extend the field to include them. In this essay I argue we should continue to see the field as complex, and maybe now a bit more so. Reflecting on field and practice theories and understandings of boundaries, I reengage the complexity that is a core demand of conceptualizing the journalistic field, while offering ways to consider interlopers' journalistic identities within its boundaries. Emphasizing similarities over differences, I argue we can move beyond binary distinctions between a field's core members and interlopers on the periphery by focusing on the nature of interloper work.
\end{abstract}

\section{Keywords}

agonism; antagonism; boundaries; core/periphery; interlopers; journalism; media

\section{Issue}

This article is part of the issue "Peripheral Actors in Journalism: Agents of Change in Journalism Culture and Practice" edited by Avery E. Holton (University of Utah, USA), Valerie Belair-Gagnon (University of Minnesota-Twin Cities, USA), and Oscar Westlund (Oslo Metropolitan University, Norway / Volda University College, Norway / University of Gothenburg, Sweden).

(C) 2019 by the author; licensee Cogitatio (Lisbon, Portugal). This article is licensed under a Creative Commons Attribution 4.0 International License (CC BY).

\section{Introduction}

On blogs and websites, and in a variety of digital spaces, the work of digital-peripheral media actors who have come into contact with the journalistic field has been the object of both curiosity and anxiety. Curiosity as these actors have shown countless new ways of bringing news to the public in a digital age, and anxiety as they have challenged previous notions of the journalistic field while doing so. As individuals motivated to do journalistic work online, this essay focuses on interlopers who enact those motivations in outspoken, critical, and aggressive ways. To the degree these interlopers have been successful in capturing public and journalistic attention they have signaled both to journalists and society more widely that a disruption of a previously consolidated profession of journalism might be under way. In this essay, I pose an argument for engaging with the work of interlopers as a way to reengage with the complexities of the journalistic field, and in doing so I build towards offering a way to differentiate between interlopers as critical journalistic friends while cautioning against opening up the field's boundaries entirely.

In referring to a category of interloper media in this essay, I focus on those media actors who claim to belong to the journalistic field while also openly criticizing traditional media and journalists they associate with institutions of power. This essay reflects on work addressed substantially in Eldridge (2018), and on recent interviews with interloping journalists carried out in 2018, in a study called Interrogating Antagonists (cf. Eldridge, 2019a; Eldridge, 2019b). This study examined the way 
interlopers reflect on their place in the journalistic field and how audiences make sense of interloper content.

The categorization of interloper media was initially developed in research examining WikiLeaks' claims of journalistic belonging, through which they argued they were more independent, more critical, and more able to hold power to account than mainstream journalistic peers (Eldridge, 2014). These dynamics have continued to emerge across research examining politicallyoriented blogs like Eschaton in the US and Order-Order in the UK, and independent websites with the Gawker and Gizmodo media groups and others (Eldridge, 2018). These studies show interloping journalists and media first seen outside the journalistic field challenging being described as outsiders by emphasizing their capacity to gather and report news, to hold political and corporate powers to account, and to report to and for their publics. They do so while repeatedly describing themselves as journalists and journalistic media, and succeeding at breaking news and in establishing a foothold in the news media environment. Nevertheless, interlopers have been widely rebuffed as not sufficiently journalistic, particularly for their provocative tone and when aiming their criticism towards other news media. However, reflecting on the nature of these interlopers, and the ways in which sharp-elbowed media work aligns with dynamics of the field, rather than merely where it signals difference, helps us account for those peripheral actors who are not only claiming but demonstrating journalistic capabilities. It also offers a way for understanding their boundary-crossing nature, and where this needs to be taken into consideration in this larger theoretical space.

While the categorization of 'interloper media' was first developed to capture how provocative new journalistic actors confronted the boundaries of the field, interloping dynamics predate this terminology. We can see interloping in the emergence of journalistic bloggers at the turn of the century, and in the rise of new actors claiming journalistic identities since (cf. Lowrey \& Gade, 2011; Robinson, 2015; Schudson \& Anderson, 2009). At first, new actors were met with curiosity, and downplayed as amateur; journalists responded to newcomers' novelty and brazenness with the quizzical response, "who are these guys?" (Singer, 2003). However, these digital newcomers have stuck around, and reactions to interlopers have turned from curiosity towards resistance. More recently, scholars have documented the building up of boundaries between a traditional journalistic field and interloping digital newcomers, as a rhetorical pushback (Carlson, 2015), in discourses casting them as outsiders who do not reflect the institutional norms of the rest of the field (Coddington, 2012), and in contradictory remarks which dismiss these new actors despite their reflecting "core journalistic values in which the profession remains heavily invested, and willing to fight for" (WahlJorgensen, 2014, p. 2588). This work shows digital newcomers seeking to have their media work recognized as journalism instead being portrayed as outsiders crossing a boundary.

In the dynamics of interloping, I see an opportunity to revisit how we make sense of a field facing uncertainty. As Ryfe $(2019$, p. 845$)$ notes, the genuine changes the field has experienced in recent years warrant such reflections, as while journalism was once shaped by "cultural threads" which were at their "densest and most cohesive" in the 20th century, those "longstanding webs of significance are unraveling." This can be attributed to a variety of developments, including the technological potential for a diverse set of actors in society to take up journalistic opportunities. As a result, journalism can no longer be assumed to be a consolidated profession able to go about its work unencumbered by external actors claiming to be journalists (Waisbord, 2013, p. 11). Ryfe $(2019$, p. 845) argues further that in the 20th century, "[j]ournalists knew who they were; they knew what counted as journalism; and they had the clearest sense they had ever had of how they were distinct from actors in other social fields," now in the 21st: "That moment has passed." It seems to me we need to understand this moment we are now in, and the nature of the journalistic field we encounter in it.

In the following sections, I outline a conceptual argument for focusing on the relationship between interlopers and the rest of the field that builds from field theory to account for interlopers and the nature of their journalistic identities. By focusing on relationships and identities, I prioritize the similarities in the way individuals understand their own journalistic identities and those of others in shaping the field. Further, I explore whether or not it continues to be useful to focus on binaries of 'cores' and 'peripheries' for our understanding of what I argue is an increasingly diverse journalistic field, one in which both traditional observant and interloping heretical actors embrace journalistic ideals (Bourdieu, 1977, p. 169; Eldridge, 2018, p. 114). In doing so, I hope to make clear where the complexity of the relationships which have traditionally shaped the journalistic field can be embraced to account for interlopers in a meaningful way.

\section{Notes on a Journalistic Field}

To set the foundation for the discussion that follows, I will focus my attention primarily on approaches from field theory. These allow us to capture the ways a group of social actors establish a distinct place in society, the social forces within and without the field that shape this distinction, and how this is promoted to a public and comes to be recognized more broadly (Benson \& Neveu, 2005; Bourdieu, 1977, 2005). In its simplest rendering, a field is a space of societal belonging, shaped first by the ways a group of social actors (in our case journalists) agree they are involved in a shared endeavor (journalism), and second in the way they promote their efficacy in performing their societal roles over and over towards society at large. In return, the field's distinction is reinforced by a public 
which agrees to see their work as valuable and different from the work of others.

For how it captures journalism's distinct societal status, the concept of the field looms large in journalism studies. It has helped scholars conceptualize how a group of social actors working across institutions, nations, genres, and media formats coalesce; a useful primer is the edited collection by Benson and Neveu (2005). Field approaches allow us to capture the relative consistency with which journalists express a "dominant vision" of the field (Bourdieu, 2005, p. 36), while also acknowledging this is the product of "invisible structures" shaping the field (Bourdieu, 2005, p. 30; cf. Schultz, 2007). Further, these approaches allow us to reflect on the way social actors, through their practices-"the sayings and doings" of their work (Schatzki, 2003; see also Ryfe, 2019)distinguish themselves from other social actors, as " $\mathrm{t}] \mathrm{o}$ exist in a field is to differentiate oneself" (Bourdieu, 2005, p. 39).

I argue that this difference-making occurs at two levels. The first is at the overall level of the field, where a field of journalism separates itself out from other fields in society by emphasizing its strength at conveying "the legitimate vision of the social world" (Bourdieu, 2005, p. 40). At this level, 'journalism' is something "held together by shared practices and values" (Ryfe \& Mensing, 2009 , p. 42) which are drawn upon by journalists in serving a public interest through the provision of news. This brings us to the second level of differentiation, at the level of individual journalists. Journalists individually separate themselves from other actors in society by amplifying their specific embodiment of shared practices and values, in contrast to those outside the field. This includes ways in which this is done subtly through assumed but unspoken criteria of belonging (Schultz, 2007), and through narratives of identity and newswork (Eldridge, 2017a), but it is also done overtly in ways meant to be seen, through discursive boundary work (Bishop, 1999; Carlson, 2015; Eldridge, 2014).

At either level, processes of differentiation (following Bourdieu) are not uninvested. They are exercises in power exerted primarily by those who already have itin our case, traditional journalistic actors who have been recognized as journalists, and their institutions which have been recognized as reflective of the journalistic field. In the interest of preserving dominant visions of the field, and minimizing contravening visions presented by interlopers, traditional actors aim to maintain the parameters of the field as best suits them. They are also more able to (in part), as they are simply more recognizable as journalists in the spaces in which they operate, giving them a greater specific weight in dictating the shape of the field; this dynamic tends to favor those with greater economic heft, rather than other indicators of quality (Benson, 2006, p. 190). This weight is thrown about in particular in response to newcomers, where the legacy of traditional actors is used as a specific distinguishing characteristic to push back against digital upstarts. This is never the more apparent than in response to interlopers seen as posing a threat to the cultural and symbolic (if not economic) capital that the traditional core of the field has amassed.

In shifting towards a more detailed discussion, there is an advantage to using field approaches to make sense of journalism undergoing change. They allow us the opportunity to extend our discussion from one of thinking of new actors in terms of their placement inside or outside the field towards one of dynamism, focusing on how the field's dimensions are shaped by relationships and interactive forces. As Bourdieu (2005) writes, the journalistic field is shaped through individual actors relating more or less to a sense of belonging to the field, as well as how they see others relating more or less to that sense of what it is to belong. Ryfe (2019) reinforces this:

If we think of journalism in this way, as a social field defined by such relationships, then it is possible to see that the cultural threads that bring it together may be more and less dense, more and less cohesive, more and less bounded, and for the field of journalism to be more and less autonomous from other social fields. (p. 845)

It's in the "more and less" where things get particularly complicated, and where notions of boundaries come into our discussion of fields, interlopers, and a journalistic core and digital periphery.

\section{The Erstwhile Core and Periphery of Journalism}

I now turn towards moving beyond research which understands the field, and changes to it, by differentiating between a traditional journalistic 'core' and a digital 'periphery.' On the one hand, distinguishing between a field's center and its edges offers a useful spatial metaphor for newcomers, designating them as something alternative, something new, and something yet to be made sense of within the bounds of journalism. On the other hand, often less productively, it suggests the field is an established space with clear dimensions (it is not). Drawing on field and practice approaches, I argue we can still focus on the construction of journalistic identities through the 'sayings' of both interlopers and traditional journalists, and how this is reflected in the work they do in order to unpack the metaphor of a journalistic core and periphery. Doing so shows where this confronts particular conceptual challenges.

To begin, I agree with Deuze and Witschge (2018), who argue a core/periphery metaphor suggests some sort of uniformity which falls apart on further inspection. As they write "the supposed core of journalism and the assumed consistency of the inner workings of news organizations are problematic starting points for journalism studies" (Deuze \& Witschge, 2018, p. 165), adding "the core is no more homogeneous than the so-called periphery" (Deuze \& Witschge, 2018, p. 168). 
They go on to advocate an abandonment of this dichotomy, in particular when trying to account for entrepreneurial and post-industrial ways of working journalistically. This seems a useful ambition, though abandoning this metaphor faces its own set of challenges, including our own tendencies as social actors to try and impose order in the face of change. I see challenges to abandoning the core/periphery metaphor as threefold.

First, as a marker for what is being referred to when discussing digital change, a core/periphery metaphor comes quite naturally to us. It offers a pivot point when addressing the questions 'change to what?' or 'to whom?' It also captures the way many digital actors see something in the 'core' of journalism which they are responding to, often by aspiring to be recognized in the same light. This is what is embodied in Donsbach's (2010, p. 38) discussion of journalism that is widely understood as societally important, but loosely defined, a journalism of 'we know it when we see it.'

The journalists interviewed in the Interrogating Antagonists study (Eldridge, 2019a, 2019b) invoke this same meaningfulness, seeing themselves alongside traditional news media as necessary complements in achieving journalism's important civic goals. As one said, reflecting on reporting on right-wing politics in the US and Europe, the outspokenness of their work complements "straightforward" traditional news. Across blogs, web sites, more activist and more antagonistic media, this ambition to be "part of that media" is a recurring feature in studies of interlopers (Eldridge, 2018, p. 4).

Second, this metaphor continues to emerge in scholarly work which has yet to find an alternative resolution to accounting for certain hard-to-accommodate newcomers. Where the core/periphery metaphor has been revised in scholarly work, it has primarily been in reconfiguring the relationship between the field and some outsiders. For instance, in breaking dichotomies which treat foreign correspondence (Archetti, 2014), lifestyle journalism (Hanusch, Banjac, \& Maares, 2019, p. 5), and other news genres as more-or-less journalistic (Loosen, 2015). In these cases, abandoning this metaphor has been empowering, bringing overlooked aspects of journalism into fuller appreciation. Yet, problematic others (and disruptive interlopers in particular) have tended to remain outside these efforts at reconfiguration.

A third challenge to abandoning this metaphor: It remains useful for capturing the sometimes-significant tensions which have come into play as journalists are confronted by change, and their tendency to instead embrace constancy. Ryfe (2019) found one such example when interviewing a journalist who threatened to punch him (in jest, presumably) were he to ever call them a 'blogger.' I have found similar reactions when bloggers, are dismissed as "not quite one of us" when compared to newspaper reporters (Sullivan, 2013, discussed in Eldridge, 2018, pp. 112-113). In these reactions, journalists minimize the disruption that change brings about by dismissing and expelling the newcomer, and a 'core' of journalism offers a comforting home. For traditional actors, coalescing around a journalistic core reinforces an understanding that they are the norm, and the 'other' is the alternative, on the periphery.

I see these three challenges as part of a rather significant set of struggles for moving away from a core/periphery understanding of the field. They signal a challenge to journalistic identity, and the sense of propriety which leads some actors to feel able to both call themselves journalists while withholding the same recognition from others. They also reflect the disruption of social status which some journalists genuinely feel, including in a challenge to their journalistic authority as new actors demonstrate their ability to also perform informative journalistic roles (Carlson, 2017). This manifests in a clash between the field's 'dominants' and upstart 'pretenders' (to use Bourdieu's terminology), which further contributes to journalists' inclination to dictate the boundaries of the field through a preservative discourse that reinforces their distinction. Such is to be expected among members of fields, where any loss of distinction is equated with demise; as Bourdieu writes: "Falling into undifferentiatedness...means losing existence, and so nothing is more threatening than the lookalike who dissolves your identity" (Bourdieu, 2005, p. 40).

When put in terms of the risk of "losing existence," the perceived threat posed by interlopers becomes existential, raising the stakes of removing the distinction between a core and a periphery. But does it mean that distinction remains terribly useful? Does it justify the boundaries which are drawn between journalists at the so-called core, and interlopers emerging from the periphery? In the next sections I will explore how the concept of interlopers has both exposed and challenged the nature of such boundaries, and how we may be able to work our way out of such distinctions without abandoning the value of the field altogether.

\section{Interlopers and Boundaries}

To capture the confrontation posed by those who now encounter the field, the concept of 'interloper media' has proven to be a simple, yet effective, conceptualization for exploring journalistic boundaries drawn in response to their emergence. It captures the socially-constructed discursive boundaries which journalists use to define their space in society, and the ways in which new actors persist to see themselves as journalists in the face of such boundary work.

To begin, journalistic boundary work is not in and of itself a problematic dynamic. Not everything mediated is journalism, not everything new which claims to be journalism needs to be recognized as such, and so boundaries can meaningfully separate different media types and different media practices in a complex digital ecosystem. Or, as Ryfe (2019, p. 850) outlines, with the rise of digital media, journalists are no longer the primary providers of news, and more actors have become 
involved in bringing news to audiences in discrete and more dynamic ways, not all of whom follow the logics of journalism, and we should not see them all as journalists. We see such boundaries when normative and traditional understandings of journalistic roles are referenced in Ryfe's (2019) interviews with veteran journalists working online who cite routines and practices as undergirding their journalistic identity, but also by bloggers who see themselves as nonjournalists precisely because they do not engage in these same routines and practices. A similar boundary is often drawn by comedians and satirists (e.g., Last Week Tonight's John Oliver or The Daily Show's former host, Jon Stewart) who point to the fact that they don't follow journalistic routines or practices to underscore why they should not be seen as journalists, even though they do present information to publics (Eldridge, 2018, p. 156).

However, the nature of boundaries found in reactive discourses towards new actors and particularly interlopers are often of a different nature. These boundaries are often more assertive, seeking to expel interlopers from the field despite their success at making, breaking, and advancing news stories which inform society. In such instances, boundaries emerge as reactions to competition over journalistic identities, first and foremost, and not as negotiations of belonging between interlopers and traditional journalists, but as one-way pronouncements dictating interlopers' non-belonging (see also Carlson \& Lewis, 2020, pp. 126-127). These discourses construct boundaries in response to interlopers by playing up difference rather than similarity. They emphasize interlopers' digital novelty, their use of biting language, slapdash presentation, niche interests, alternative storytelling approaches, etc., and downplay acknowledgement of any journalistic similarities (Eldridge, 2018, p. 92). Such boundaries are drawn in reactions to disruptive interlopers in particular, and have been found in reactions to other digital actors, including journalistic bloggers, entrepreneurs, and startups (Duffy, 2019; Hepp \& Loosen, 2019; Witschge \& Harbers, 2019). They emerge despite interlopers' material contributions to wider news agendas, made when they report and produce news which is then followed up on by other journalists (Eldridge, 2019c).

We can understand these boundaries as preservative discourses, where confronted by the novel approaches to newcomers' work and the compositions of their organizations, journalists respond by trying to preserve the "collectively shared and taken-for-granted assumptions underlying the belief that journalists, acting in their normative roles, ought to wield gatekeeping control over news content on behalf of society" (Lewis, 2012, p. 845). This occurs even when we have many examples where the very same normative roles, and the same routines and practices invoked by traditional journalists, are also employed in the way interlopers identify their work as journalism. Indeed, where Ryfe (2019) describes 'nonjournalists' pointing to traditional practices of journal- ists as reasons for excluding themselves from the field, in my own work and others' (cf. Hepp \& Loosen, 2019; Witschge \& Harbers, 2019), digital newcomers point to the way they take up the same "sayings and doings" of journalistic practice as reasons for including themselves in the field. These actors identify in their work a sense of continuity with the journalistic field, and see these shared ambitions as a lodestar which they use to attune their work towards the journalistic field, aligning themselves and their media work in terms of serving society as journalistic peers.

Interlopers tend to see their work as journalism despite specific differences and because of overall similarities, including similarities with traditional practices. These provide the foundation for their journalistic identities, and they express this in seeking positive recognition of their newswork. This includes similarities of reporting and content ("the manner in which I do my job is different than other journalists, but I think that the end result is the same," said one interviewee in the Interrogating Antagonists study (Eldridge, 2019a); another, describing the "drip drip" nature of publishing short snippets of reports over time, said: "What tends to happen after we do it half a dozen times, the newspapers will say 'well this is a real issue' and some people pick it up and it becomes a story").

At the same time, these identities and the construction of journalistic belonging and non-belonging are not always static, and quite often they are nonpermanent dispositions. In line with the complexity of the field, these also need to be considered in terms of relations and forces which are context-based. For instance, one interviewee in the Interrogating Antagonists study (cf. Eldridge 2019a) said she considered herself less of a journalist when blogging for some news sites and more so when writing for others, pointing specifically to reporting practices as the distinguishing criteria. Another said she saw herself as having similar ambitions as journalists, but her role was facilitating their practices through design work. Externally, we may also see certain interlopers as more journalistic sometimes, and less-so at other times.

In this light, however, we might better understand those journalistic boundaries we do find narrated by traditional actors as reactions to the risk of "undifferentiatedness" which new actors seem to pose, and which Bourdieu (2005, p. 40) emphasizes as an existential threat to the field. From that viewpoint, it certainly makes sense that traditional journalists might be hesitant to accept interlopers as fellow journalists, as this would diffuse the strength of their own journalistic identity. Further, from this angle, we can recognize that those who have traditionally been at the core of the field, embedded in its institutions and traditional outlets, have little interest and much at stake in acknowledging interlopers as peers.

But these dynamics should not require scholars to reinforce this apprehension in work which tries to make 
sense of interlopers, or any new actors who might confront the boundaries of the field. Rather, work should try to recognize the anxiety faced by those in traditional roles, while pushing past this point to also understand where such boundaries fail us in developing full understanding of a dynamic field undergoing change. To return to Ryfe's (2019) point referenced above, in a complex digital ecosystem not all news comes from journalists, and so not all new actors need to be seen as journalists. I would agree, but argue further that there are many among this new group of actors making news public who do in fact see themselves as journalists, regardless of their different approaches to delivering news to publics. For that we should take into consideration whether or not we too, as scholars, can see them as journalists.

This discussion has highlighted a point I have argued previously as to the limit of what a focus on boundaries can offer us in accounting for the emergence of new actors. The reaction is interesting, but can be predictable, and locating boundaries should not be an endpoint to examining change (Eldridge, 2018, p. xi). For one, attention placed on boundaries alone can inaccurately suggest an impregnable wall between a field of journalism and non-journalistic outsiders. On one hand, if boundaries indeed operated in this way, we would expect to see those at the core of the field avoiding any reference to work from the periphery. Yet, we regularly find references to interlopers' work, particularly when interloper content holds those in power to account or exposes otherwise neglected news stories, and when their work provides jumping off points which traditional actors build from, perhaps saying things in ways other journalists wish they could (Eldridge, 2019c). On the other hand, if these boundaries reflected the field's dimensions fittingly, we wouldn't expect to see those on periphery trying to associate themselves with the more traditional core, describing their journalistic identities in normative ways. Yet we see this as well, and often in ways that resonate traditional ideals of journalism (Eldridge, 2018, p. 125).

There is an opportunity in these points of coming together, however, as it allows us to see where the construction of boundaries highlights how a changing field embraces a measure of continuity amid a raft of digital change (Eldridge, Hess, Tandoc, \& Westlund, 2019, p. 388). Taking this up allows us to see the field as facing challenges both internal-as cohesion over long-held imaginations of the field's boundaries slips-and external, as new actors broach the field's boundaries. And we have good cause to push forward such an agenda revisiting the nature of the field and the complexity of journalism's boundaries at the points where they are constructed. Vos and Singer (2016, p. 144) make this case, describing the field's boundaries as "continually subject to disruption by both exogenous and endogenous forces." We are buoyed further by work which has focused on disruptive interlopers, but also work developing alternative understandings of interlopers, intralopers (Belair-Gagnon \& Holton, 2018), strangers (Holton \&
Belair-Gagnon, 2018), and in-betweeners (Ahva, 2017). These remind us of the significant complexities in understanding journalism's dynamism around its edges.

In both the reticence of some newcomers to be described as journalists, and the eagerness of other newcomers to be recognized as journalists, we can find a fruitful place to locate such a revised agenda. While interlopers confront the nature of boundaries, they have also signaled the resilience of dominant ideas of journalism. Or, put differently, research shows that in focusing on the differences made evident by boundary work, and not similarities found with those pushing to cross over such lines, we certainly find boundaries, but also risk leaving something out. This raises the question as to whether, as scholars, we would be better served by focusing not on differentiation, but on the degree to which the differences drawn between a dominant journalistic core and an emergent digital periphery are faithful reflections of the abilities of those occupying either space, and whether such differentiation accounts for the full breadth of actors who avail themselves of the shared practices and values which unite the field in the first place.

This is particularly important for understanding a field undergoing change as boundaries focused on difference will naturally highlight distinctions between those who have been traditionally been recognized as journalists and afforded the cultural and symbolic capital which benefits from that legacy, disadvantaging interloping newcomers who do not yet have this capital at hand. Boundaries on their own reinforce a hegemonic and path-dependent understanding of the field, and can obscure a more complex understanding of the nature of interlopers' journalistic work.

\section{The Field of Relations}

One way forward from this is to reengage with seeing journalism as a field being forged amid these forces and in the meeting up of those pushing out from the core of the field and those pushing in from the periphery. Focusing on these forces may help conceptualize the field more fully. The field, in this exercise, is not conceived by its boundaries as a space of entry or expulsion, so much as it is a space of social relations. In that sense it can be seen as something constructed by those who identify themselves as belonging to the field, and those who embrace its contributions. This allows us to maintain a tether of continuity to the traditional understanding of the journalistic field, including how its ideals are shared by many, while also accounting for the change posed by interlopers. Further, this allows us to acknowledge the existential risk of undifferentiatedness which prompts some journalists to highlight difference, alongside the importance of a shared sense of belonging shaping the journalistic field-e.g., what guides journalists to say 'we are journalists,' and how does that inform their feeling that 'we do journalism.' 
The impetus for these expressions is located in the doxa and the habitus, or the inherent sense of belonging (doxa) and the specific socialized dispositions guiding practice (habitus). The doxa is a rather unspoken sense of belonging (Schultz, 2007), and something "which is beyond question and which each agent tacitly accords" (Bourdieu, 1977, p. 169). The dispositions of the habitus are shaped by the "invisible structures" which shape their social positioning, and the dominant vision central to the field involves field members agreeing to look past differences amongst themselves in the interest of coalescing (Bourdieu, 2005, p. 30; Eldridge, 2017b). These two aspects join a third (nomos) in the field's sense of vision and division (belonging and distinction) which guide practices.

While differentiation is key to individuals associating themselves with one field over another, similarity also plays a role. For the vision of the field to be coherent:

Even the most irreducible adversaries have in common that they accept a certain number of presuppositions that are constitutive of the very functioning of the field. In order to fight one another, people have to agree on the areas of disagreement. (Bourdieu, 2005, p. 36)

With the journalistic field, these dynamics enable journalists (both traditional and interloping, I argue) to orient their belonging. Yet as invisible structures shaping the field, their ability to express such belonging differs. For instance, the socialized disposition of the habitus and the inherent criteria of belonging reflected in the doxa may be expressed by both interlopers and traditional journalists, but it may be more quickly recognized in the work of traditional actors who have the benefit of legacy and prominence in expressing their belonging (see the points raised by Benson, 1999, 2006, above, and below).

However, the invisibility of these forces also provides an opportunity. If the doxa is somehow both inherent and unspoken, and the habitus shaped by exogenous and endogenous social forces we can't always see (Vos \& Singer, 2016, p. 144), and the vision shaped in part by smoothing over differences (Bourdieu, 2005, p. 36), we can draw on this thread further to ask: If socialized belonging (doxa) rests on assumed senses of belonging among journalistic actors, surely as the universe of possible journalistic actors has expanded, we can argue for a revisiting of these assumptions? Further, if the socialized structures of the journalistic field (habitus) and its guiding sense of vision and division (nomos) were already being perceived differently by different journalists in the 20th century who simply agreed to overlook these differences, with the scale of digital change surely all these differences and invisibilities can no longer be plastered over?

Benson offers a useful prelude to this discussion, posed before the breadth of digital journalism we now observe came into being. He noted how the "field of jour- nalism (as with all other fields) is structured around the opposition between the 'old' and the 'new"' (Benson, 1999, p. 467). So, one need not see different interpretations of the field's structures, dispositions, and visions as a roadblock. Instead, through "analysis of new entrants into a field, media field researchers also add an important dynamic element to the model, showing how the 'objective' structure is related to the 'subjective' perspectives of individual agents" (Benson, 1999, p. 167). In other words, one can consider the nature of digital change at the material level-objective structuresalongside the ways these changes shape individuals' subjective perspectives - the journalistic doxa, informed by the habitus. This approach allows scholars to examine how agents, both new and old, position themselves as working in the furtherance of society. It enables seeing these dynamics as forces with greater fluidity, embraced and acted upon differently by different societal actors.

Now to be clear, for some journalists, traditional vision of the journalistic field, even accepting this reorientation, will still resonate. These journalists would defend the doxa in terms of a journalistic orthodoxy, or what Bourdieu describes as a natural way of being reinforced through "a system of euphemisms, of acceptable ways of thinking and speaking" (Bourdieu, 1977, p. 169). They may rely on a highly-traditional dominant vision built on journalism's history and its institutions in shaping their habitus. Such journalists are not rare, rather they are the products of the socialization processes of journalism which led towards institutionalized coherence in the 20th century (Ryfe, 2006), embracing grand narratives (Peters \& Witschge, 2015), and the normative expectations of the field (Eldridge \& Steel, 2016). If there were to be a journalistic core, these journalists would be at the middle of it.

But these journalists are no longer alone in the news environment, and it can no longer be assumed that their vision is universally agreed-to. Instead, interlopers who also express a journalistic doxa and habitus have intensified both the nature and the visibility of struggles between the field's most observant, orthodox, members and those seen-as-blasphemous, heretical challengers (Benson, 1999, p. 472). Simultaneously, because these struggles are now more visible, there is an opportunity for reengaging field theory to account for an expanded set of actors, both newer and older.

I argue we should do so with a greater emphasis on similarity, rather than difference, and the threads for such an approach have already been found. For instance, we can locate how interlopers express similar doxic ideals of informing the public in its interest, and holding power to account (an ideal of "punching up," as one interviewee described it [Eldridge, 2019a]), they just go about this differently in practice, and do so enabled by the affordances of digital media and their independence from larger institutional constraints ("once you have resigned yourself to the fact that you will never have the access to certain people or certain places, then you can be a lot 
more honest in what you are doing" she added [Eldridge, 2019a]). We can further find similarity with the vision of the field when this work is then embraced both by members of the public and by journalists who build upon their work. This was made visible in 2003 with revelations from j-bloggers like Axios at Eschaton, and more recently with Tim Burke reporting for Deadspin; both showed how interlopers gather and publish news, which is then reported on further by 'mainstream' outlets who share in the same news agenda (Eldridge, 2018, 2019c).

Rather than attend to difference, which might otherwise define the field narrowly, choosing to focus on similarities among a diverse set of actors helps to find points of agreement between interlopers and those who see them as interloping. But, as with any effort revising our approaches to understanding society, we must remain mindful of limits to reconfiguring something as socially embedded as journalism, and consider where to maintain a certain degree of 'differentiatedness' in order to continue seeing journalism as a field, just a more diverse and dynamic one. Therefore, if we want to understand journalism more complexly by expanding its boundaries, we must ask to what extent this is feasible, and how we can be inclusive without conceptualizing our ideas of journalism so vastly they become meaningless. We must revisit where and how we draw such lines.

\section{Considering Antagonism and Agonism}

To build on this, I suggest a useful distinction can be found in the nature of relating, both between interlopers and traditional journalists but also their relationships with publics, including in how their work conveys these relationships. This focuses not on the discrete practices of actors, as these are varied and constantly changing with new forms of content and ways of enacting journalistic routines, but on the expressed or apparent intentionality of these activities, and how they correspond with a journalistic vision. This requires approaching provocative, sharp-tongued, and critical interlopers not as 'antagonistic' outsiders to be rebuffed by boundaries of expulsion (as they have often been seen), but as operating on a spectrum between 'agonism' and 'antagonism.'

In this suggestion, I adopt Mouffe's $(2000$, p. 7) differentiation between 'agonism' as a description of constructive disagreement (the actions of an adversarial friend) and 'antagonism' as destructive opposition (the outsider enemy). Agonism can be found in the work of Deadspin's Burke, mentioned above, who highlighted the way a conservative media owner close to the U.S. president was pressuring local news stations to read a specific political script (Eldridge, 2019c). It can also be found in reporting on Eschaton or Gawker which critiqued mainstream news media for missing prominent political news stories (e.g., a Senator's endorsement of a segregationist politician on Eschaton, or the closeness of the US State Department and Washington DC journalists on Gawker). They further urged traditional media to follow up on that reporting (Eldridge, 2018, pp. 142-143, 161-162). In these instances, agonism is located in a critical metadiscourse. Focusing on the constructive adversarial nature of interlopers posing such critiques allows scholars to look at the critical voice of interlopers as positive when they push against journalistic complacency, as long as it is aligned with journalistic ideals of revealing truths, and holding power to account, among others.

Antagonism can be found in work from Breitbart or Wikileaks as two media outlets which, at times, perform traditional informative journalistic routines, while at other times-particularly in 2016-they use the guise of journalism to disguise more antagonistic ambitions, serving political agendas rather than public ones. I have elsewhere referred to this as the 'malappropriation' of a journalistic identity (Eldridge, 2018, pp. 166-167), and when it masks hidden agendas, this malappropriation is antagonistic towards the field of journalism writ large. In these cases, claims of journalistic identity and criticism of 'complacent' media are outweighed by the nature of content which serves specific political mechanisms which does not carry journalistic ideals or values.

Making this distinction between an aggressive agonist and a destructive antagonist is not always straightforward. It first requires distinguishing between an antagonistic voice and an antagonistic relationship. We find (and can countenance) agonism in a complex field even when it adopts an antagonistic voice of critical "punching up" in interlopers' work-really, in all journalistic work-where it is directed at those who have power in society (the state, for instance). We can also see agonism as fitting within the field when critical metadiscourses are honestly directed at powerful journalistic actors. This was seen in the antagonistic voice adopted by Wikileaks in 2010 and 2011, when its revelations drove journalistic work even as it criticized mainstream media (Eldridge, 2014). An antagonistic voice has also been regularly expressed by Eschaton and sites once affiliated with Gawker which criticized journalists' hob-knobbing with politicians (Eldridge, 2018, pp. 132-133).

This antagonistic voice is a characteristic of the interloper-as-agonist; as a critical friend working towards the same socio-informative role as other journalists. When we see this, we may be minded to bring such activities within the boundaries of the field. We should perhaps embrace this opportunity even more so when criticism is directed towards both ideological allies and obvious enemies. Interlopers, in this dynamic, are embracing journalistic ideals, just with sharp elbows and sharper tongues.

At the same time, scholars should continue to decry those who adopt an antagonistic relationship towards the field, particularly when embedding anti-civic or antijournalistic intentions. This includes manipulating information, sharing disinformation, or serving politicians rather than publics, as with WikiLeaks' leaks in 2016 of Hillary Clinton's emails, working, seemingly, as a Russian cutout. It also includes Gawker's invasion of the wrestler 
Hulk Hogan's privacy under the guise of journalism (Eldridge, 2018). Antagonism in these cases is fundamentally destructive, as it hides political agendas and misuses public trust, undermining the nature of journalism by disguising such agendas as public-interested news.

Antagonistic relationships are important reminders that an agenda to reengage with the complexity of the field is not an invitation to upend it entirely. From Bourdieu (2005), seeing the field as a group of social actors sees these actors agreeing they are "playing the same game" (p. 30). When interlopers embrace similar practices or identify with journalistic values, but do so in new ways, we can see them as sitting within a pluralist field of journalism. In this pluralist field, they may be agonists, but they nevertheless play the same game.

In such an orientation, interlopers are highly visible reminders of the complexity which shapes the journalistic field, and draw our attention to the struggles which define it. While interlopers would be rougher-fitting members of the journalistic field if defining it by the distinctions favored by the traditional core, when turning to focus on the nature of their relationship with that field, and the journalistic appeal at the heart of much of their work, as agonists they seem within its boundaries.

\section{Limitations}

In nuancing the relationship between interlopers and other journalists as one of agonism or antagonism, I aim to move our discussions beyond seeing boundaries as hard distinctions drawn between actors, and rather as a space of forces surrounding the field. However, there are limits to consider. The first is a consideration of our objects of study, the second is how we study them.

First, while a dynamic understanding of the journalistic field has been a consideration among many scholars, it has not always been reflected in the reactions of journalists who continue to be (understandably) inclined towards harder boundaries. Their perspectives still need to be weighed in considering how much of our scholarly reflections on fields are also reflected in practice. However, to the degree journalists' perspectives matter for shaping the field (and they do), I would caution against a reliance on journalists' perspectives alone as a definer of the field, as this elides the more complex reality (so too would I caution against relying on the perspectives of interlopers to see the extent to which they fit, as surely they too benefit from a boundary drawn which places them within the field's dimensions).

Second, this essay has highlighted where scholars focusing on similar phenomena from different perspectives reach different conclusion about fields. One builds a sense of the field as united by the routines and practices (this is reflected in Ryfe's, 2019, argument), another in a shared dominant vision of journalism's function, as I have argued. Both are developed in an attempt to understand the field more complexly, and draw on similar developments of disruption and change in a digital age.
In focusing on practices, Ryfe finds that difference reinforces distinction and, as a result, locates a "curious resilience of some aspects of traditional journalism within a generally disruptive environment" (Ryfe, 2019, p. 844). To his point about resilience, I would agree. In research examining interlopers and reactions to them, I have also found a persistent idea of what journalism should be embraced by interlopers, though they often locate it in identities rather than practices.

Both approaches emphasize how actors adhere to journalism's importance to society, holding power to account, and providing fact-based news to their publics, among other shared attributes. However, where I depart from Ryfe's findings is in the way my own work has shown the resilience of this idea inspiring not separation but journalistic belonging among interlopers. This does not mean one of these findings is more correct than the other, rather it is a matter of conceptual lenses and where attention is paid. Based on practices, digital newcomers may identify difference in that they do not also perform the practices of traditional journalism such as reporting a beat, or other similar institutional routines (Ryfe, 2019). It's a distinction others have drawn as well (Peters, 2011). In these cases, practice provides a point of difference between newcomers and traditional actors. Though closely aligned, other conceptual lenses from field theory allow us to take a different tack, seeing where a dominant central vision or an interpretation of a journalistic doxa of what it means to belong to the field of journalism gives an aspirational center point around which interlopers and journalists both coalesce, despite differences in practice (Benkler, 2011; Eldridge, 2018). From this perspective, similarities-sharing a sense of a journalistic doxa, habitus, and dominant vision-allow us to locate belonging, drawing interlopers into the field, even if traditional journalists might rather push them away.

\section{Conclusion}

What emerges from the discussion here is a more complex engagement with the journalistic field which brings forward a nuanced view of interlopers. I hope to have offered an understanding of their position within the field that would be missed out upon if we focused primarily on reactions to interlopers from traditional actors who are predisposed towards differentiating between a core and a periphery. The preservative impetus embraced by members of the field who "risk falling into undifferentiatedness" should also not be dismissed lightly (Bourdieu, 2005 , p. 40). Even for interlopers the societal distinction of journalism matters. This is reflected in the way interlopers draw inspiration from traditional ideals while also embracing an opportunity to do things differently. That they do so while using sharp, critical, voices towards those they see as letting down the shared ideals of the field reflects this as even when critical of their peers' work, interlopers see this criticism as serving to improve 
the broader field of journalism. This reminds scholars that both difference and similarity are woven together in the identities of interlopers who see themselves as enacting new imaginations of journalistic ideals. As research into interlopers has shown, for traditional journalists and interlopers alike a powerful idea of what journalism means for society still matters. It may matter differently and it may be understood differently by each, but it certainly matters.

Working this complexity into our discussions of the field allows us to review our approach towards boundaries as well, seeing these as increasingly blurred and porous, and arrived at through the meeting up of societal forces which ebb and flow in strength. When we step away from the preservative boundaries which are drawn by journalists heavily invested in their own status being confirmed, we may see these boundaries not as lines but as something of a graduated spectrum, with antagonistic outsiders on one end, and agonistic critical friends on the other. This enables seeing interlopers as journalists when they align with the field's shared ambitions, just doing so differently, with sharper elbows, ready to punch up a bit when it is called for.

\section{Acknowledgments}

My thanks to the editors for their support and to reviewers for their feedback in the development of this essay. The Interrogating Antagonists project was funded by a $€ 3,000$ grant under the University of Groningen Faculty of Arts "Start-up Grant" scheme for developing new research. My gratitude to Nathalie Fridzema, Research Assistant on this project.

\section{Conflict of Interests}

The author declares no conflict of interests.

\section{References}

Ahva, L. (2017). How is participation practiced by "in-betweeners" of journalism? Journalism Practice, $11(2 / 3), 142-159$.

Archetti, C. (2014). Journalism and the city. Journalism Studies, 15(5), 586-595.

Belair-Gagnon, V., \& Holton, A. (2018). Boundary work, interloper media, and analytics in newsrooms. Digital Journalism, 6(4), 492-508.

Benkler, Y. (2011). A free irresponsible press. Harvard Civil Rights-Civil Liberties Law Review, 46, 311-397.

Benson, R. (1999). Field theory in comparative context: A new paradigm for media studies. Theory and Society, 28(3), 463-498.

Benson, R. (2006). News media as a "journalistic field." Political Communication, 23(2), 187-202.

Benson, R., \& Neveu, E. (2005). Bourdieu and the journalistic field. Oxford: Wiley.

Bishop, R. (1999). From behind the walls: Boundary work by news organizations in their coverage of Princess Diana's death. Journal of Communication Inquiry, 23(1), 90-112.

Bourdieu, P. (1977). Outline of a theory of practice. Cambridge: Cambridge University Press.

Bourdieu, P. (2005). The political field, the social science field, and the journalistic field. In R. Benson \& E. Neveu (Eds.), Bourdieu and the journalistic field (pp. 29-47). Cambridge: Polity.

Carlson, M. (2015). Introduction: The many boundaries of journalism. In M. Carlson \& S. C. Lewis (Eds.), Boundaries of journalism (pp. 1-18). Abingdon: Routledge.

Carlson, M. (2017). Journalistic authority. New York, NY: Columbia University Press.

Carlson, M., \& Lewis, S. (2020). Boundary work. In. K. Wahl-Jorgensen \& T. Hanitzsch (Eds.), The handbook of journalism studies (2nd ed., pp. 123-135). Abingdon: Routledge.

Coddington, M. (2012). Defending a paradigm by patrolling a boundary: Two global newspapers' approach to WikiLeaks. Journalism \& Mass Communication Quarterly, 89(3), 377-396.

Deuze, M., \& Witschge, T. (2018). Beyond journalism: Theorizing the transformation of journalism. Journalism, 19(2), 165-181.

Donsbach, W. (2010). Journalists and their professional identities. In S. Allan (Ed.), The Routledge companion to news and journalism (pp. 38-59). Abingdon: Routledge.

Duffy, A. (2019). Out of the shadows: The editor as a defining characteristic of journalism. Journalism. Advance online publication. https://doi.org/10.1177/ 1464884919826818

Eldridge, S. A., II. (2014). Boundary maintenance and interloper media reaction. Journalism Studies, 15(1), $1-16$.

Eldridge, S. A., II. (2017a). Hero or anti-hero? Narratives of newswork and journalistic identity construction in complex digital megastories. Digital Journalism, 5(2), 141-158.

Eldridge, S. A., II. (2017b). Dissolving boundaries. In M. Burger, R. Fitzgerald, \& J. Thornborrow (Eds.), Places, spaces and discursive actions in social media and real communicative environments (pp. 221-238). Brussels: De Boeck.

Eldridge, S. A., II. (2018). Online journalism from the periphery: Interloper media and the journalistic field. London: Routledge.

Eldridge, S. A., II. (2019a). Agonists and antagonists: Journalistic knowledge production and acquisition with digital-peripheral journalism. Paper presented at ECREA Journalism Studies Conference "Breaking Binaries: Exploring the Diverse Meanings of Journalism in Contemporary Societies," University of Vienna, Vienna, Austria.

Eldridge, S. A., II. (2019b). Journalism in the spaces between: Journalistic outsiders and publics as critical 
definers of journalism. "Future of Journalism Conference: Innovations, Transitions and Transformations," Cardiff University, Cardiff, Wales.

Eldridge, S. A., II. (2019c). 'Thank god for Deadspin': Interlopers, metajournalistic commentary, and fake news through the lens of 'journalistic realization.' New Media \& Society, 21(4), 856-878.

Eldridge, S. A., II, Hess, K., Tandoc, E. C., \& Westlund, O. (2019). Navigating the scholarly terrain: Introducing the digital journalism studies compass. Digital Journalism, 7(3), 386-403.

Eldridge, S. A., II, \& Steel, J. (2016). Normative expectations. Journalism Studies, 17(7), 817-826.

Hanusch, F., Banjac, S., \& Maares, P. (2019). The power of commercial influences. Journalism Practice. Advance online publication. https://doi.org/10.1080/ 17512786.2019.1682942

Hepp, A., \& Loosen, W. (2019). Pioneer journalism: Conceptualizing the role of pioneer journalists and pioneer communities in the organizational re-figuration of journalism. Journalism. Advance online publication. https://doi.org/10.1177/1464884919829277

Holton, A., \& Belair-Gagnon, V. (2018). Strangers to the game? Interlopers, intralopers, and shifting news production. Media and Communication, 6(4), 70-78. http://dx.doi.org/10.17645/mac.v6i4.1490

Lewis, S. C. (2012). The tension between professional control and open participation. Information, Communication \& Society, 15(6), 836-866.

Loosen, W. (2015). The notion of the "blurring boundaries." Digital Journalism, 3(1), 68-84.

Lowrey, W., \& Gade, P. (2011). Changing the news. Abingdon: Routledge.

Mouffe, C. (2000). The democratic paradox. London: Verso.

Peters, C., \& Witschge, T. (2015). From grand narratives of democracy to small expectations of participation. Journalism Practice, 9(1), 19-34.
Peters, J. (2011). WikiLeaks would not qualify to claim federal reporter's privilege in any form. Federal Communications Law Journal, 63(3), 667-695.

Robinson, S. (2015). Redrawing borders from within. In M. Carlson \& S. C. Lewis (Eds.), Boundaries of journalism (pp. 152-168). Abingdon: Routledge.

Ryfe, D. (2006). New institutionalism and the news. Political Communication, 23(2), 135-144.

Ryfe, D. (2019). The warp and woof of the field of journalism. Digital Journalism, 7(7), 844-859.

Ryfe, D., \& Mensing, D. (2009). Citizen journalism in a historical frame. In J. Rosenberry \& B. St. John III (Eds.), Public journalism 2.0 (pp. 32-44). Abingdon: Routledge.

Schatzki, T. (2003). The site of the social: A philosophical account of the constitution of social life and change. College Station, PA: Penn State University Press.

Schudson, M., \& Anderson, C. W. (2009). News production and organizations. In K. Wahl-Jorgensen \& T. Hanitzsch (Eds.), The handbook of journalism studies (1st ed., pp. 88-101). Abingdon: Routledge.

Schultz, I. (2007). The journalistic gut feeling. Journalism Practice, 1(2), 190-207.

Singer, J. (2003). Who are these guys? Journalism, 4(2), 139-163.

Vos, T., \& Singer, J. (2016). Media discourse about entrepreneurial journalism. Journalism Practice, 10(2), 143-159.

Wahl-Jorgensen, K. (2014). Is Wikileaks challenging the paradigm of journalism? International Journal of Communication, 8, 2581-2592.

Waisbord, S. (2013). Reinventing professionalism: Journalism and news in global perspective. Cambridge: Polity.

Witschge, T., \& Harbers, F. (2019). The entrepreneurial journalist. In S. A. Eldridge II \& B. Franklin (Eds.), The Routledge handbook of developments in digital journalism studies (pp. 86-98). Abingdon: Routledge.

\section{About the Author}

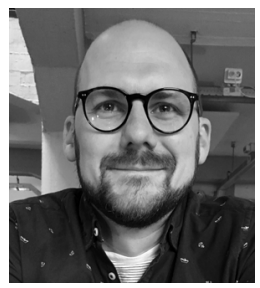

Scott A. Eldridge II is an Assistant Professor with the Centre for Media and Journalism Studies at the University of Groningen. His recent publications on digital change and the journalistic field include Online Journalism from the Periphery (2018), the edited volumes The Routledge Companion to Digital Journalism Studies (2017), and The Routledge Handbook of Developments in Digital Journalism Studies (2019) with Bob Franklin, as well as articles in Journalism \& Communication Monographs, New Media \& Society, Journalism Studies, and Media and Communication. 